\title{
ANALISIS DAN PERANCANGAN SISTEM INFORMASI PERPUSTAKAAN SMA NEGERI XYZ
}

\author{
Titan; Devyano Luhukay; Yohannes Kurniawan \\ Information Systems Department, School of Information Systems, Binus University \\ Jln. K.H. Syahdan No. 9, Palmerah, Jakarta Barat 11480 \\ titan@binus.edu; devyano@binus.edu; ykurniawan@binus.edu
}

\begin{abstract}
Library information system analysis and design for public senior high school XYZ in South Tangerang aims to identify needs of data and information about library operational transaction in the school. The result of requirement analysis was used to build a computerized system supporting the run of library business process. The analysis and design focused on solving the problems, such difficulties in finding book location, book availability, and else. Rational Unified Process was used for the information system development methodology and the result of requirement analysis was documented by using unified modeling language; user interface was also designed. This information system was expected to ease the library in doing its activity by serving the information related to book searching, book availability, book tracking. Besides, it would also fasten the process of book borrowing, book returning, and new book registration.
\end{abstract}

Keywords: library information system, library system, school library

\begin{abstract}
ABSTRAK
Analisis dan perancangan sistem informasi untuk perpustakaan SMA Negeri XYZ di Tangerang Selatan bertujuan untuk mengidentifikasi kebutuhan perpustakaan sekolah dalam pengelolaan data dan informasi terkait transaksi operasional perpustakaan. Hal ini dilakukan agar dibangun sebuah sistem terkomputerisasi yang dapat mendukung kegiatan operasional perpustakaan. Sistem informasi yang dibangun diharapkan dapat mengatasi permasalahan-permasalahan, seperti kesulitan untuk mencari lokasi buku, ketersediaan buku, dan lainnya. Metodologi pengembangan sistem informasi yang digunakan berdasarkan Rational Unified Process. Hasil analisis terhadap kebutuhan didokumentasikan dengan menggunakan unified modeling language. Rancangan sistem baru ditampilkan dengan menggunakan rancangan layar. Kehadiran sistem informasi ini diharapkan maтрu mempermudah kegiatan operasional di perpustakaan tersebut dengan menyediakan informasi terkait pencarian buku, ketersediaan buku, tracking buku, serta mempercepat proses peminjaman buku, pengembalian buku dan pendaftaran buku baru.
\end{abstract}

Kata kunci: sistem informasi perpustakaan, sistem perpustakaan, perpustakaan SMA 


\section{PENDAHULUAN}

Pada era globalisasi seperti ini teknologi informasi telah berkembang dengan pesat. Kehadiran teknologi dalam dunia bisnis menjadi hal yang sangat penting dalam mendukung kegiatan bisnis yang berjalan di suatu perusahaan serta memberikan nilai tambahan bagi perusahaan guna memenangkan persaingan. Selain digunakan oleh perusahaan-perusahaan, kehadiran teknologi juga sudah mulai banyak diadaptasi oleh lembaga-lembaga pendidikan seperti sekolah hingga perguruan tinggi,yaitu bahwa teknologi berperan dalam mendukung kegiatan pembelajaran para peserta didiknya. Hal ini terlihat dari mulai banyaknya lembaga pendidikan yang memberi sentuhan teknologi terhadap fasilitas-fasilitas yang dimiliki, seperti learning management system, kehadiran access point, sampai kehadiran perpustakaan online.

Perpustakaan adalah salah satu fasilitas lembaga pendidikan yang sangat berperan penting dalam menunjang pembelajaran para peserta didik. Koleksi literatur yang dimiliki di dalamnya harus dikelola secara terorganisasi guna memberikan pelayanan yang memuaskan pada para customer. Akan tetapi, masih banyak sistem pencatatan transaksi dari perpustakaan yang menggunakan cara sederhana seperti pencatatan transaksi ke dalam buku atau Microsoft Excel.

Sebuah perpustakaan salah satu SMA Negeri XYZ di Tangerang Selatan masih melakukan hal demikian untuk pencatatan transaksi perpustakaan. Maka tidak heran jika banyak data peminjaman atau pengembalian buku yang hilang, atau bahkan adanya koleksi literature yang tidak terdata. Hal-hal seperti ini berdampak pada sulitnya mendapatkan informasi yang pasti dan real terhadap jumlah koleksi literatur yang tersedia untuk dipinjam.

Analisis dan perancangan sistem informasi untuk perpustakaan SMA Negeri XYZ di Tangerang Selatan bertujuan untuk mengidentifikasi kebutuhan perpustakaan SMA Negeri XYZ dalam pengelolaan data dan informasi terkait transaksi operasional dari perpustakaan. Hal itu untuk membangun sebuah sistem terkomputerisasi yang dapat mendukung berjalannya operasional perpustakaan SMA Negeri XYZ di Tangerang Selatan tersebut. Kegiatan analisis dan perancangan ini berfokus pada aktivitas-aktivitas yang terjadi di perpustakaan SMA Negeri XYZ di Tangerang Selatan, seperti pendaftaran buku, peminjaman buku, pengembalian buku, pemesanan buku, penerimaan buku, dan sebagainya. Sistem informasi perpustakaan yang dirancang diharapkan mampu menyelesaikan permasalahan yang ada di perpustakaan SMA Negeri XYZ. Ke depannya, sistem informasi ini juga diharapkan dapat memenuhi kebutuhan perpustakaan sekolah pada umumnya, sehingga bukan tidak mungkin jika sistem informasi ini juga digunakan di perpustakaan-perpustakaan sekolah lainnya.

\section{Tinjauan Literatur}

Menurut Satzinger et al (2005), sistem informasi adalah komponen yang saling berhubungan yang mengoleksi, memproses, menyimpan, dan menyediakan luarab informasi yang dibutuhkan untuk menyelesaikan tugas-tugas bisnis. Sedangkan menurut Rainer et al (2007), sistem informasi adalah proses mengumpulkan, memproses, menyimpan, menganalisis, dan menyebarkan informasi untuk suatu tujuan spesifik. Sementara itu, menurut Bennet (2010), sistem informasi adalah proses mengumpulkan data dan menggunakannya untuk menghasilkan suatu informasi yang berguna untuk sebagian orang tertentu dalam suatu konteks tertentu.

Perpustakaan, menurut Kamus Besar Bahasa Indonesia (2005), adalah pertama, tempat, gedung, ruang yang disediakan untuk pemeliharaan dan penggunaan koleksi buku. Kedua, koleksi buku, majalah, dan bahan kepustakaan lainnya yang disimpan untuk dibaca, dipelajari, dibicarakan. 


\section{METODE}

Metode yang digunakan dalam penulisan makalah ini adalah tinjauan pustaka, analisis, dan perancangan untuk membangun sistem informasi perpustakaan di SMA Negeri XYZ, Tangerang Selatan. Langkah awal dalam melakukan analisis adalah dengan melakukan observasi terhadap tata laksana sistem yang sedang berjalan. Setelah itu, wawancara dilakukan terhadap pihak pejabat sekolah, pengelola perpustakaan, dan para peserta didik. Hasil observasi dan wawancara, kemudian, dianalisis lebih lanjut guna mengidentifikasi kebutuhan sistem informasi perpustakaan yang akan dibangun. Dokumentasi dari hasil analisis menggunakan unified modeling language yang didasarkan pada unified process disciplines (Satzinger, 2005). Hasil analisis kemudian digunakan untuk perancangan sistem yang diusulkan. Aplikasi dibangun dengan menggunakan bahasa pemrograman C\# dan SQL Server 2005 sebagai database.

\section{HASIL DAN PEMBAHASAN}

\section{Tata Laksana Sistem Berjalan}

Salah satu SMA Negeri XYZ di Tangerang Selatan ini berdiri sejak 2002. Jumlah siswa saat ini mencapai 634 siswa dengan tenaga pendidik sebanyak 43 orang. Pada saat pertama kali dibangun, sekolah terletak di kecamatan Pondok Aren, namun sejak Banten memasuki masa periode jabatan baru dengan gubernur Banten yang baru, yaitu Ratu Atut sebagai Gubernur, penamaan sekolah negeri di daerah Banten berubah mengikuti nama kabupaten.

Berikut adalah proses bisnis berjalan terkait dengan aktivitas di perpustakan. Penjaga perpustakaan bekerja menangani setiap kegiatan yang terjadi di perpustakaan SMA Negeri XYZ Tangerang Selatan. Kegiatan tersebut meliputi peminjaman, pengembalian buku, pencatatan buku masuk, pembuatan nomor seri buku. Selain itu, perpustakaan juga memberlakukan sanksi jika buku hilang atau rusak atau buku telat dikembalikan.

Lalu, untuk meminjam buku, siswa dapat langsung mendatangi perpustakaan SMA Negeri XYZ Tangerang Selatan. Untuk mencari buku, siswa dapat bertanya langsung kepada penjaga perpustakaan yang sedang menjaga perpustakaan. Penjaga perpustakaan akan mencari ketersediaan buku yang dicari di buku catatan ketersediaan buku. Catatan berisi nomor seri buku, judul buku, pengarang, penerbit, dan tahun terbit. Sedangkan rak buku disusun berdasar pengelompokan jenis buku. Selain itu, siswa juga bisa mencari buku yang dicari dengan langsung mencari buku yang ingin dipinjam di rak buku. Kemudian siswa memberikan buku yang ingin dipinjam ke penjaga perpustakaan, lalu akan dicatat oleh penjaga perpustakaan dalam buku catatan peminjaman yang merangkap sekaligus sebagai buku catatan pengembalian, dan pencatatan kehilangan/kerusakan atau denda. Buku ini berisi nomor catatan, nama siswa, kelas, judul buku yang dipinjam, jumlah, tanggal pengembalian, dan tanda tangan. Peminjaman buku dibatasi maksimal 3 buah buku, dengan lama peminjaman buku paling lama 10 hari. Selebihnya, jika telat siswa akan dikenakan sanksi berupa denda.

Setelah meakukan peminjaman, warga sekolah mengembalikan buku kepada penjaga perpustakaan yang sedang berjaga. Kemudian penjaga perpustakaan akan mencari nama siswa di buku catatan peminjaman dengan menyamakan judul buku yang dipinjam, kemudian akan diberi tanda oleh penjaga perpustakaan sebagai tanda buku tersebut sudah dikembalikan. Jika buku dikembalikan melebihi tanggal pengembalian, siswa akan dikenakan sanksi berupa denda. Namun karena perpustakaan ini baru dibangun dan pengunjungnya masih terhitung sedikit, peraturan ini belum 
diterapkan; siswa hanya dikenakan peringatan. Meskipun begitu, aturan yang ada mengharuskan siswa membayar sejumlah uang untuk setiap keterlambatan pengembalian buku. Nilai uang ini akan dikalikan dengan jumlah buku yang dipinjam. Jika saat dikembalikan buku dalam keadaan rusak, siswa wajib mengganti buku yang rusak. Buku yang rusak akan diberikan untuk siswa, sedangkan buku pengganti akan diberikan kepada pihak perpustakaan SMA Negeri XYZ Tangerang Selatan. Untuk buku yang hilang, siswa wajib mengganti buku yang hilang dengan buku yang baru dan diserahkan kepada pihak perpustakaan SMA Negeri XYZ Tangerang Selatan.

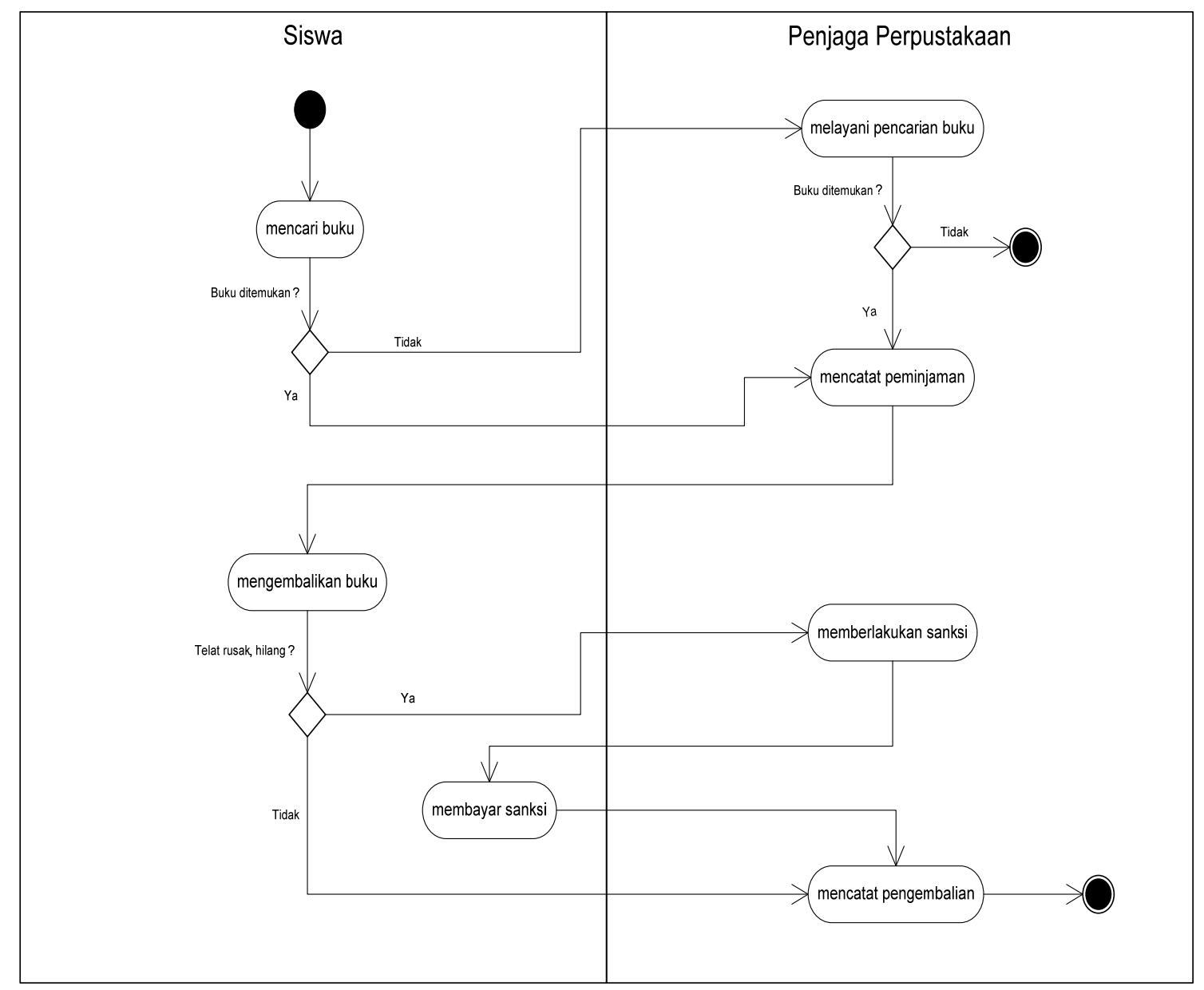

Gambar 1 Diagram Aktivitas Peminjaman dan Pengembalian Buku

Selain menangani peminjaman, pengembalian buku, dan pencatatan kehilangan/kerusakan atau denda, penjaga perpustakaan juga bertanggung jawab atas pencatatan buku masuk dan pembuatan nomor seri buku. Setiap buku baru yang akan masuk ke dalam koleksi buku di perpustakaan SMA Negeri XYZ Tangerang Selatan, akan dimasukkan ke buku catatan ketersediaan buku. Penjaga perpustakaan pertama-tama akan membuatkan nomor seri buku yang unik dan mencatat detail buku lainnya ke dalam buku catatan ketersediaan buku. 


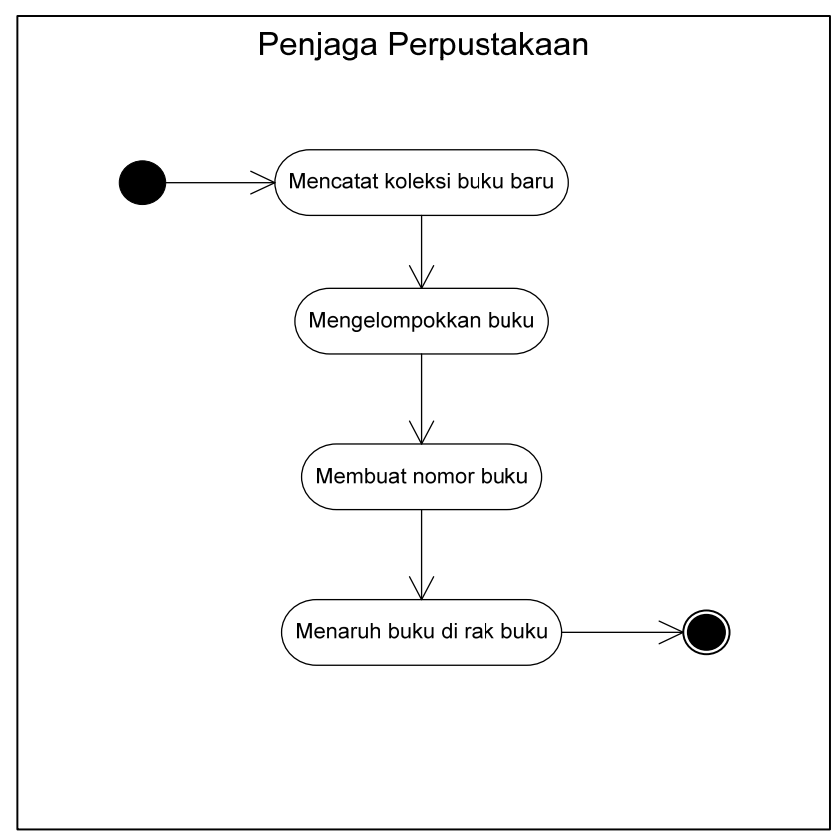

Gambar 2 Diagram Aktivitas Akuisisi Buku

Dari hasil analisis terhadap tata laksana sistem berjalan, diketahui permasalahan yang dihadapi adalah sebagai berikut. Pertama, penjaga perpustakaan kesulitan dalam mengetahui keberadaan buku. Kedua, penjaga perpustakaan mengalami kesulitan dalam mengetahui ketersediaan buku. Ketiga, adanya indikasi dapat dilakukan kecurangan dalam aktivitas pengembalian buku, bahwa otorisasi pengembalian yang berupa tanda tangan dapat ditiru siswa.

\section{Usulan Pemecahan Masalah}

Berdasarkan permasalahan yang dihadapi, pemecahan masalah yang diusulkan adalah sebagai berikut. Pertama, melakukan analisis dan perancangan sistem informasi perpustakaan agar dapat menerapkan sistem yang lebih baik. Kedua, mengembangkan sistem informasi perpustakaan yang terkomputerisasi untuk perusahaan dengan mengembangkan sebuah aplikasi yang memiliki fitur tracking buku, penomoran buku terotomatisasi, pembedaan hak akses untuk user, serta peminjaman dan pengembalian buku yang terhubung dengan database. Gambar 3 berikut menerangkan fitur-fitur dari sistem informasi yang diusulkan. 


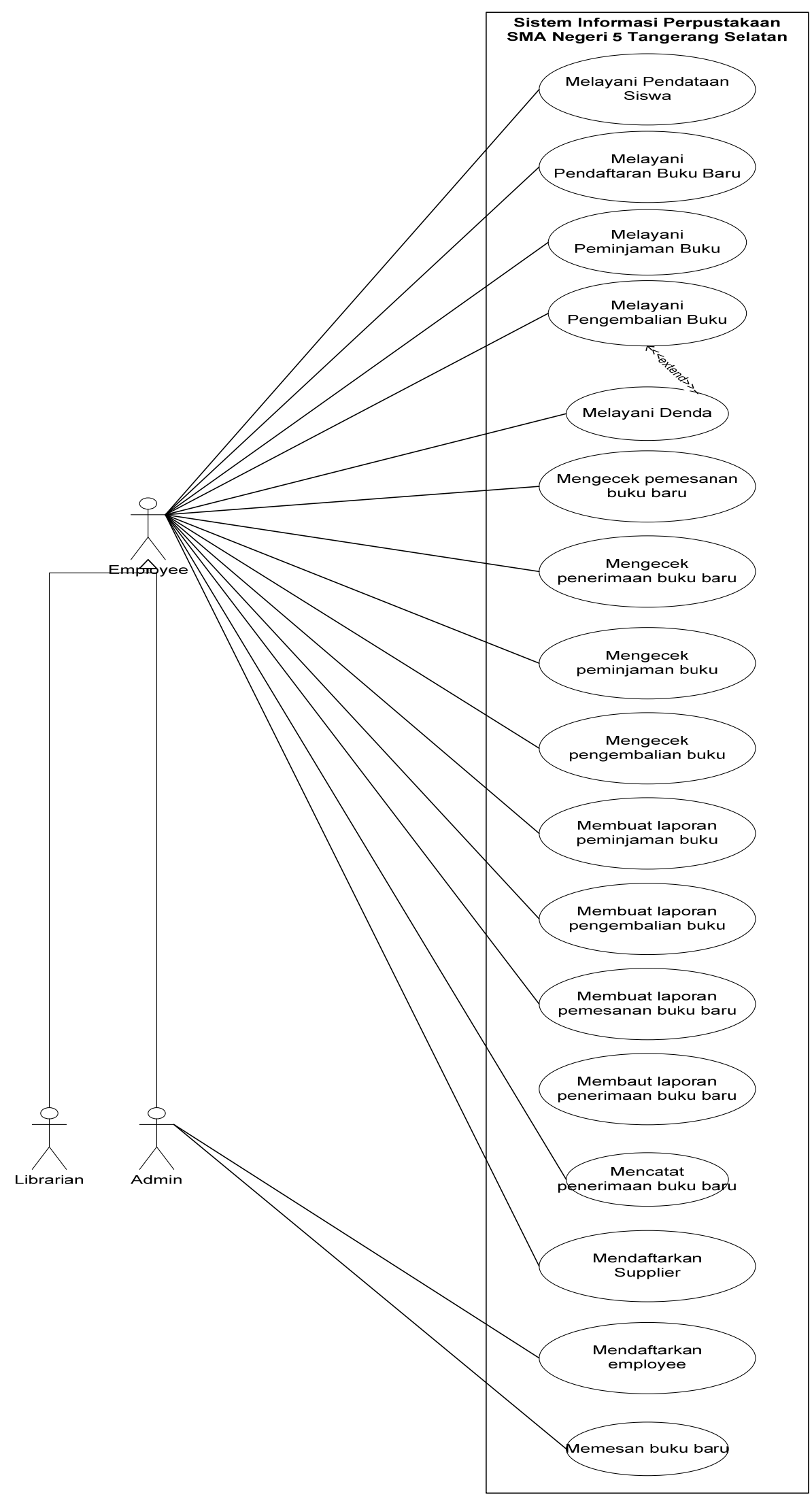

Gambar 3 Use Case Diagram 
Fitur-fitur dari sistem informasi yang diusulkan digambarkan sesuai dengan Gambar 3. Akses beberapa fitur akan dibatasi tergantung dari hak akses user tersebut.

Kebutuhan data perpustakaan terhadap sistem informasi yang diusulkan untuk SMA Negeri XYZ di Tangerang Selatan dijelaskan melalui Gambar 4 berikut ini.

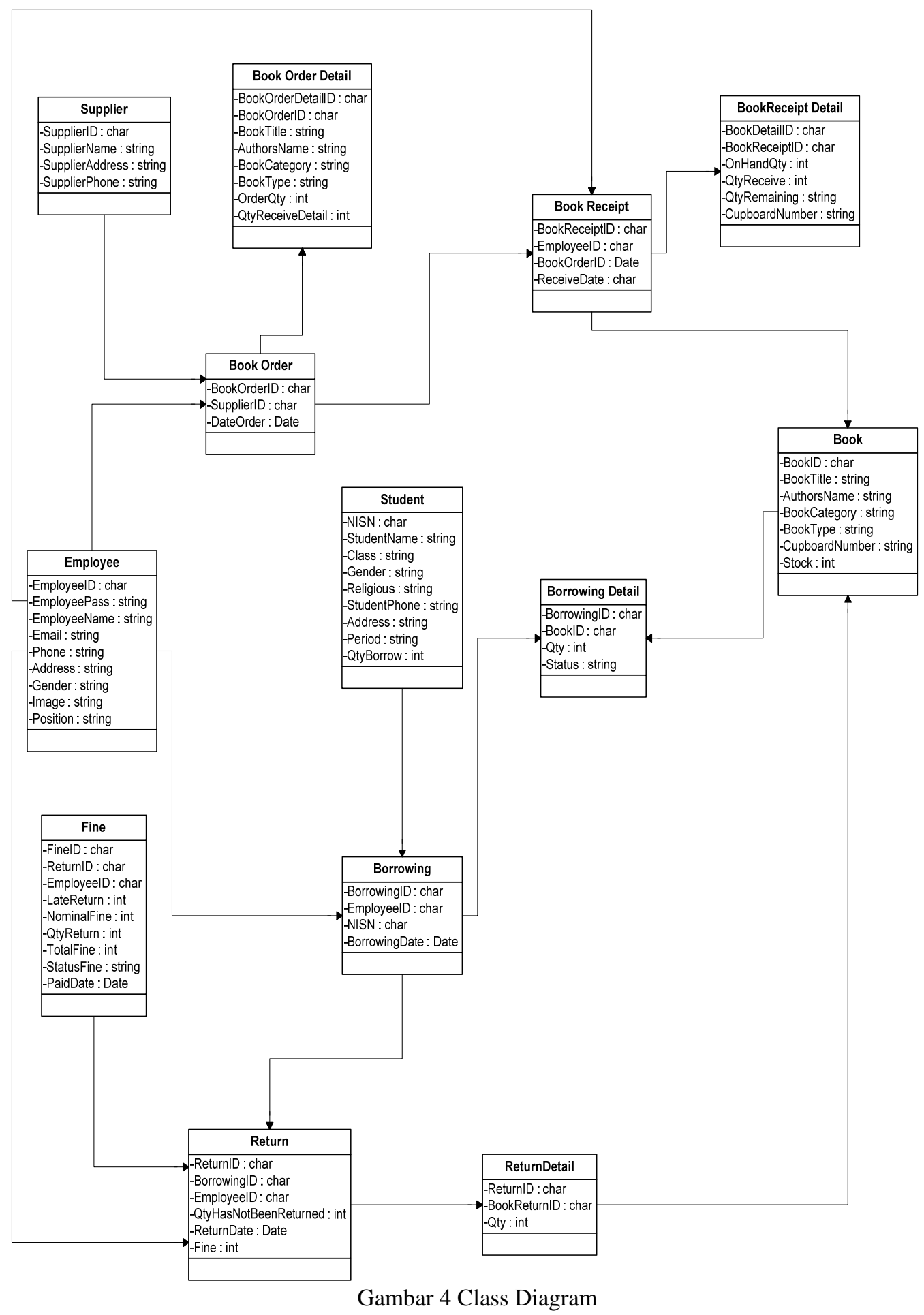




\section{User Interface}

User interface yang dibuat dalam pembangunan sistem informasi perpustakaan SMA Negeri di Tangerang Selatan adalah sebagai berikut: (1) user interface untuk Master Book, (2) user interface untuk Master Student, (3) user interface untuk Master Employee, (4) user interface untuk Master Supplier, (5) user interface untuk Borrowing Books, (6) user interface untuk Returning Books, (7) user interface untuk Order Books, (8) user interface untuk Receipt Book Order, (9) user interface untuk Borrowing Fine, (10) user interface untuk View Borrow-Return Transaction, (11) user interface untuk Check Book Order, (12) user interface untuk Book Acquisitions Report, (13) user interface untuk Return Report, (14) user interface untuk Book Order Report, (15) user interface untuk Book Receipt Report, (16) user interface untuk Borrowing Report. Gambar 5, 6, 7, dan 8 berturut-turut menunjukkan Form Master Book, Borrowing Books, Returning Books, dan Book Receipt.

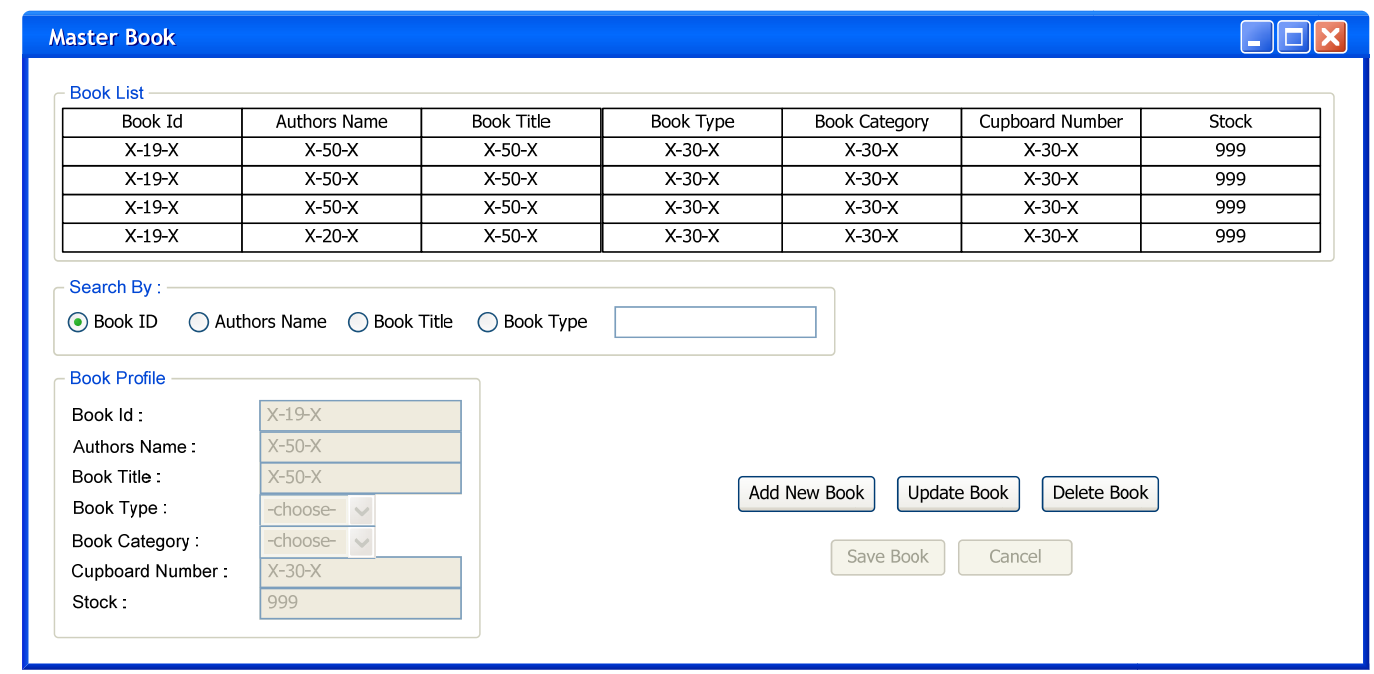

Gambar 5 Form Master Book

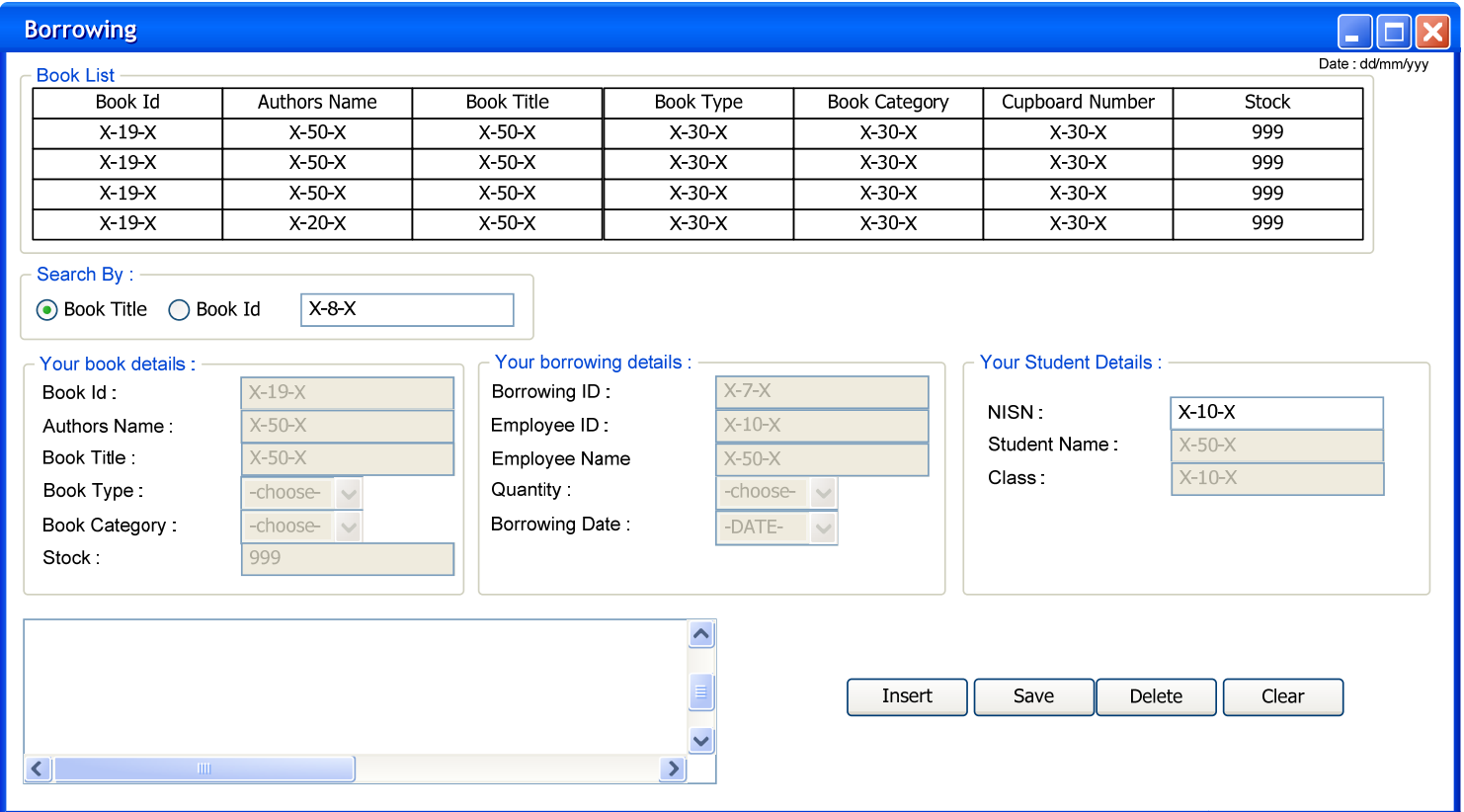

Gambar 6 Form Borrowing Books 


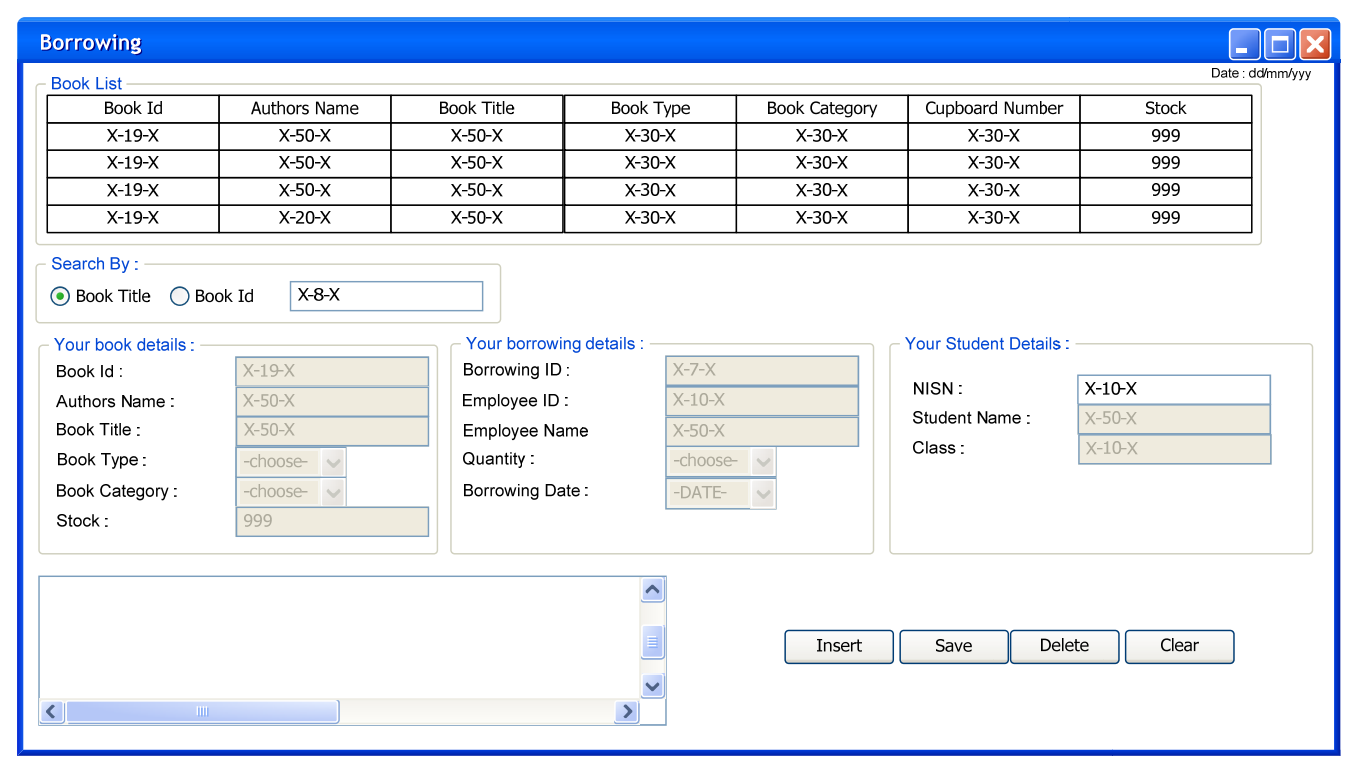

Gambar 7 Form Returning Books

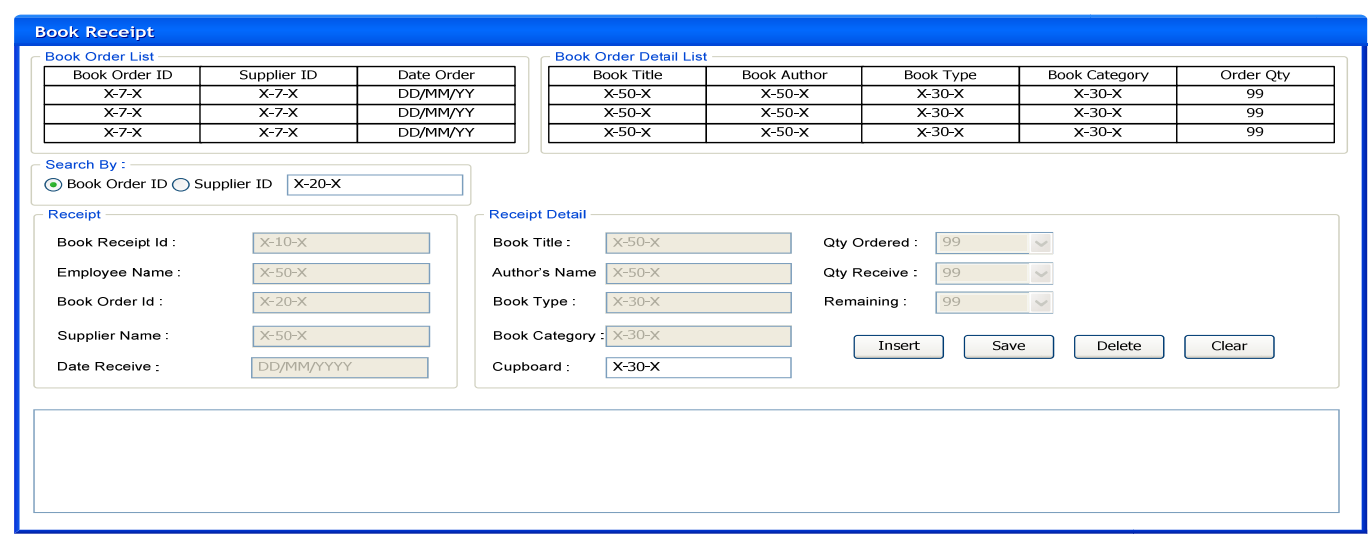

Gambar 8 Form Book Receipt

\section{SIMPULAN}

Berdasarkan hasil analisis dan perancangan sistem informasi perpustakaan SMA Negeri di Tangerang Selatan, dapat disimpulkan hal-hal sebagai berikut. Pertama, kehadiran sistem informasi perpustakan dapat mempermudah proses pendaftaran, peminjaman, pengembalian buku, pemesanan, dan penerimaan buku. Kedua, kehadiran sistem informasi perpustakaan memungkinkan untuk memantau koleksi buku yang belum dikembalikan. Ketiga, kehadiran sistem informasi perpustakaan memudahkan dalam mengetahui lokasi buku. Keempat, adanya pembatasan hak akses terhadap pengguna system. Kelima, adanya fitur pencatatan buku baru dengan penomoran buku yang autogenerate berdasarkan kategori buku. Dan keenam, kehadiran sistem yang terkomputerisasi mampu mengatasi masalah kehilangan data yang dibutuhkan dalam menjalankan proses bisnis di dalam perpustakaan. Berikut ini beberapa saran yang diharapkan dapat berguna untuk pengembangan sistem informasi perpustakaan SMA Negeri di Tangerang Selatan. Pertama, back-up data dilakukan secara berkala. Kedua, mulai mempertimbangkan untuk mengembangkan aplikasi yang berbasis web yang dapat diakses oleh para customer perpustakaan SMA Negeri di Tangerang Selatan. 


\section{DAFTAR PUSTAKA}

Bennett, Simon, McRobb, Steve, Farmer, Ray .(2010). Object-Oriented Systems Analysis and Design Using UML ( $4^{\text {th }}$ Edition $)$. New Jersey: Pearson Prentice Hall.

Hasan, A., dkk. (2005). Kamus Besar Bahasa Infonesia. Jakarta: Balai Pustaka

Rainer, R. K., Turban, E., \& E. Potter, E. (2007). Introduction to Information Systems: Supporting and Transforming Business. UK: John Wiley \& Sons, Inc.

Satzinger, J. W., Jackson, R. B., \& Burd, S. D. (2005). Object Oriented Analysis and Design with the Unified Process. USA: Course Technology. 